\title{
The importance of apoptosis for immune regulation in Chagas disease
}

\author{
George A DosReis $/{ }^{+}$, Marcela F Lopes \\ Instituto de Biofísica Carlos Chagas Filho, Centro de Ciências da Saúde, Universidade Federal do Rio de Janeiro, Bloco G, Ilha do Fundão, \\ 21941-902 Rio de Janeiro, RJ, Brasil
}

Host cell apoptosis plays an important immune regulatory role in parasitic infections. Infection of mice with Trypanosoma cruzi, the causative agent of Chagas disease, induces lymphocyte apoptosis. In addition, phagocytosis of apoptotic cells stimulates the growth of $\mathrm{T}$. cruzi inside host macrophages. In spite of progress made in this area, the importance of apoptosis in the pathogenesis of Chagas disease remains unclear. Here we review the evidence of apoptosis in mice and humans infected with T. cruzi. We also discuss the mechanisms by which apoptosis can influence underlying host responses and tissue damage during Chagas disease progression.

Key words: apoptosis - lymphocytes - phagocytosis - cytokines - Trypanosoma cruzi

Programmed cell death by apoptosis is a biological response relevant for development, tissue renewal and homeostasis of the immune system. Defects in the regulation of apoptosis can lead to disease (Rudin \& Thompson 1997). Apoptosis can also be induced in unicellular parasites, including Trypanosoma cruzi (Ameisen et al. 1995, Piacenza et al. 2001). Apoptosis of a proportion of Leishmania parasites is required for successful establishment of infection in the vertebrate host (van Zandbergen et al. 2006). In addition, infective forms of Leishmania spp. and T. cruzi display extracellular phosphatidylserine, a marker of apoptotic cells that is involved in host macrophage inactivation and increased parasite replication (de Freitas Balanco 2001, Damatta et al. 2007). Upon infection with parasites, host leukocyte apoptosis plays an important immune regulatory role (DosReis et al. 2007). In spite of progress made in this area, the importance of apoptosis for the pathogenesis of Chagas disease remains unclear. Here we review the evidence of apoptosis in mice and humans infected with $T$. cruzi. We also discuss the mechanisms by which apoptosis can influence host responses and tissue damage underlying Chagas disease.

Host cell apoptosis in T. cruzi infection and the immunosuppressive effect of apoptotic cells

Infection of fibroblasts and cardiomyocytes with $T$. cruzi either delays or induces host cell apoptosis, depending on the experimental system employed (de Souza et al. 2003, Petersen et al. 2006). In addition, infection with

Financial support: CNPq, FAPERJ, TDR-WHO (Switzerland), Howard Hughes Medical Institute (USA), the Guggenheim Foundation (USA)

+ Corresponding author: gdosreis@biof.ufrj.br

Received: 3 March 2009

Accepted: 20 May 2009
T. cruzi leads to T and B- lymphocyte apoptosis (Lopes et al. 1995a, Martins et al. 1998, Zuniga et al. 2002, de Meis et al. 2006), which can impact immune responses.

To investigate apoptosis, we infect mice with chemically induced metacyclic trypomastigotes. By all tested parameters, this model is identical to infection induced by insect-derived trypomastigotes (Lopes et al. 1995a). Restimulation of $\mathrm{CD} 4^{+} \mathrm{T}$ cells from mice infected with T. cruzi results in in vitro formation of large cell clusters where most lymphocytes die. The cells that are excluded from the clusters remain viable, suggesting a fratricide mechanism of activation-induced cell death (AICD). Cell death occurs by apoptosis, as demonstrated by transmission electron microscopy and by nucleosome sized DNA fragmentation (Lopes et al. 1995b). Data gathered from independent experiments reveal a linear correlation between the extent of suppression of T-cell responses and the amplitude of AICD (Lopes \& DosReis 1996). These results suggest that the immune suppression underlying acute infection with T. cruzi (Harel-Bellan et al. 1983) can be ascribed to AICD. The Fas apoptotic pathway plays an important role in the regulation of immune responses (Krammer et al. 2007). AICD in $T$. cruzi infection is mediated, at least in part, by the Fas pathway, since it is blocked by neutralizing anti-Fas ligand (FasL) antibodies and is absent in FasL deficient gld mice (Lopes et al. 1999). Studies employing more virulent isolates suggest that suppression of T-cell responses can also result from apoptosis induced by excess nitric oxide production (Martins et al. 1998).

Infection with T. cruzi leads to polyclonal lymphocyte activation (Minoprio et al. 1989), which, by itself, promotes T-cell apoptosis (Welsh \& McNally 1999). In addition, antigens released by T. cruzi, such as trans-sialidase and HSP70, induce lymphocyte apoptosis (Leguizamón et al. 1999, Marañón et al. 2000). Therefore, it is possible that the parasite exploits host cell apoptosis in order to evade the immune response. To investigate the impact of lymphocyte apoptosis on parasite replication, infected macrophages are cultured with $\mathrm{T}$ cells from infected mice. Apoptosis is induced in T cells and intracellular 
parasite load is assessed in macrophages (Nunes et al. 1998). Induction of $\mathrm{CD}^{+} \mathrm{T}$ cell apoptosis by in vitro TCR co-aggregation or Fas stimulation amplifies T. cru$z i$ growth, and a neutralizing anti-FasL $\mathrm{mAb}$ blocks both AICD and parasite growth (Nunes et al. 1998). Separation of $\mathrm{T}$ cells and macrophages by a cell-impermeable membrane prevents parasite growth (Nunes et al. 1998), suggesting that phagocytosis of dead cells is required for parasite survival.

Apoptosis leads to rapid and silent removal of dead cells by neighbouring cells and professional phagocytes (Ravichandran \& Lorenz 2007). Dead cell clearance is followed by the immunosuppressive effects of apoptotic cells, which impair secretion of IL-12 (Voll et al. 1997) and induce secretion of TGF- $\beta$ by engulfing macrophages (Fadok et al. 1998). Phagocytes express an array of innate receptors to recognize, tether and engulf apoptotic cells, most of which are directed to exposed phosphatidylserine molecules (Ravichandran \& Lorenz 2007). One such receptor is the integrin $\alpha_{\mathrm{y}} \beta_{3}$, which binds phosphatidylserine through the opsonin milk fat globule-EGF factor 8 (MFG-E8) or lactadherin, a glycoprotein secreted by macrophages (Hanayama et al. 2002). Transglutaminase 2 binds to both MFG-E8 and $\alpha_{\mathrm{v}} \beta_{3}$ and is required to stabilize the adhesion of apoptotic cells to phagocytes (Tóth et al. 2009). In addition, the integrin $\alpha_{v} \beta_{3}$ binds thrombospondin on the surface of apoptotic cells (Savill et al. 1992). Macrophages infected with T. cruzi support increased parasite replication when exposed to apoptotic lymphocytes (Nunes et al. 1998, Freire-de-Lima et al. 2000). The clue for this biological effect comes from the observation that $T$. cruzi is unable to synthesize the essential polyamine putrescine and depends on the uptake of exogenous putrescine for intracellular growth (Ariyanayagam et al. 2003). Binding of apoptotic lymphocytes to $\alpha_{v} \beta_{3}$ expressed by macrophages leads to PGE ${ }_{2}$ and TGF- $\beta$ production, followed by the induction of ornithine decarboxylase (ODC) and the synthesis of putrescine, which functions as a growth factor for intracellular forms of $T$. cruzi (Freire-de-Lima et al. 2000). This deleterious effect of apoptotic cells is abolished by inhibitors of prostaglandin synthesis and by neutralizing antibodies against TGF- $\beta$ (Freire-de-Lima et al. 2000).

\section{Consequences of apoptosis for development of new therapies against $T$. cruzi}

These results suggest that lymphocyte apoptosis followed by phagocytic removal helps the establishment of T. cruzi infection. In agreement with this finding, injection of apoptotic cells increases parasitemia in vivo. On the other hand, injection of cyclooxygenase inhibitors aspirin and indomethacin, which block production of TGF- $\beta$ and polyamines, reduces parasitemia (Freirede-Lima et al. 2000). Treatment with cyclooxygenase inhibitors can lead to different outcomes, depending on the protocol employed (Celentano et al. 1995, Freire-deLima et al. 2000, Michelin et al. 2005, Hideko Tatakihara et al. 2008). The continuous use of cyclooxygenase inhibitors, particularly in resistant mouse strains, leads to higher mortality (Celentano et al. 1995, Hideko Tatakihara et al. 2008).
One important question is how to target cell death for the modulation of immune responses during T. cruzi infection. During T. cruzi infection, apoptosis can be induced through at least three distinct pathways: (i) extrinsic soluble or membrane attached ligands for death receptors, such as Fas, (ii) granzymes released by cytotoxic cells and (iii) the intrinsic mitochondrial pathway. The key event in cell death signalling is the activation of caspases and the cleavage of target substrates. In order to understand whether the mechanisms of apoptosis involve the extrinsic or intrinsic pathways, we used inhibitors of caspase-8 and caspase-9 (Silva et al. 2005, de Meis et al. 2008). One criticism is that the specificity of these inhibitors occurs only at low doses (Pereira \& Song 2008). For understanding the role of individual caspases, a combination of strategies such as the use of genetically modified mice and the injection of caspase inhibitors reinforce each other (Silva et al. 2005). These experiments indicate that $\mathrm{T}$ cells from infected mice undergo apoptosis through the extrinsic pathway (Silva et al. 2005). Two distinct approaches are used to block apoptosis in T. cruzi infection: in vivo injection of neutralizing antibody to FasL (Guillermo et al. 2007) or treatment with the general caspase inhibitor zVAD (Silva et al. 2007). Treatment with zVAD or anti-FasL reduces apoptosis and improves type-1 immune responses. T cells produce more IFN- $\gamma$ and macrophages show increased control of intracellular infection. Moreover, both strategies reduce parasitemia, possibly by sustaining protective immune responses (Guillermo et al. 2007, Silva et al. 2007). A possible consequence of blocking apoptosis is to increase the number of inflammatory cells in target tissues. On the other hand, inhibition of tissue cell death may improve tissue function (Guillermo et al. 2009). In T. cruzi infection, treatment with anti-FasL, but not zVAD, increases inflammatory infiltrates in the hearts. It is unknown whether this effect helps to control infection or enhances tissue dysfunction (Guillermo et al. 2009).

\section{Apoptosis and cardiac inflammation in Chagas disease}

Apoptosis can be identified in parasites, cardiomyocytes and in inflammatory cells in heart tissues from dogs and mice acutely infected with $T$. cruzi (Zhang et al. 1999, de Souza et al. 2003). In addition, apoptosis can be identified in cardiomyocytes and inflammatory cells in heart tissue from chagasic patients, a finding associated with heart failure (Tostes et al. 2005). An immune regulatory role for apoptosis is indicated by the findings of low peripheral blood mononuclear cell proliferative responses to T. cruzi antigens, increased levels of Fas and FasL expression, and increased apoptosis in association with heart failure in Chagas disease patients (Rodrigues et al. 2008). In addition, another study suggests that the expression of FasL and Fas regulates the extent of cardiac inflammation and cardiomyocyte destruction in T. cruzi infection (de Oliveira et al. 2007). Taken together, these studies suggest a causal link between apoptosis and heart damage, but the mechanisms involved are unclear. 
The immunosuppressive effects of apoptotic cell removal suggest that it plays a role in the resolution of inflammation. However, apoptosis can promote inflammation and autoimmunity, depending on the inflammatory context of apoptotic cell removal. Concomitant exposure to apoptotic cells and a Toll-like receptor (TLR) ligand, such as bacterial lipopolysaccharide (LPS), leads to proinflammatory cytokine secretion by phagocytes (Lucas et al. 2003). In addition, immunization with apoptotic cardiomyocytes and LPS results in autoimmune myocarditis (Eriksson et al. 2003). In this regard, it is noteworthy that $T$. cruzi expresses unmethylated $\mathrm{CpG}$ motifs in DNA, which are ligands for TLR9 (Bartholomeu et al. 2008). One hypothesis suggests that phagocytosis of apoptotic parasites and cardiomyocytes by immature dendritic cells in the presence of TLR ligands leads to dendritic cell maturation and priming of T cells against parasite and self cardiac antigens (DosReis et al. 2005).

The identification of deleterious effects of apoptotic cells and their effect on $T$. cruzi replication provides a new conceptual framework for the pathogenesis and treatment of Chagas disease. However, several questions remain unsolved, including the role of apoptosis in cardiac inflammation and the therapeutic efficacy of blocking host cell apoptosis. The high incidence of apoptosis in abnormal $\mathrm{T}$ cells from mice deficient in Fas signalling, together with the general immune defects of mice carrying a T-cell specific deficiency in caspase-8 (Wu et al. 2004), make the evaluation of the role of apoptosis more difficult. Mice deficient in selected pathways of cell death, the use of RNA interference to block cell death and the development of more selective caspase inhibitors could be useful future approaches to determine the importance of apoptosis for the pathogenesis of Chagas disease.

\section{REFERENCES}

Ameisen JC, Idziorek T, Billaut-Mulot O, Loyens M, Tissier JP, Potentier A, Ouaissi A 1995. Apoptosis in a unicellular eukaryote (Trypanosoma cruzi): implications for the evolutionary origin and role of programmed cell death in the control of cell proliferation, differentiation and survival. Cell Death Differ 2: 285-300.

Ariyanayagam MR, Oza SL, Mehlert A, Fairlamb AH 2003. Bis (glutathionyl) spermine and other novel trypanothione analogues in Trypanosoma cruzi. J Biol Chem 278: 27612-27619.

Bartholomeu DC, Ropert C, Melo MB, Parroche P, Junqueira CF, Teixeira SM, Sirois C, Kasperkovitz P, Knetter CF, Lien E, Latz E, Golenbock DT, Gazzinelli RT 2008. Recruitment and endolysosomal activation of TLR9 in dendritic cells infected with Trypanosoma cruzi. J Immunol 181: 1333-1344.

Celentano AM, Gorelik G, Solana ME, Sterin-Borda L, Borda E, González Cappa SM 1995. PGE2 involvement in experimental infection with Trypanosoma cruzi subpopulations. Prostaglandins 49: 141-153.

Damatta RA, Seabra SH, Deolindo P, Arnholdt AC, Manhães L, Goldenberg S, de Souza W 2007. Trypanosoma cruzi exposes phosphatidylserine as an evasion mechanism. FEMS Microbiol Lett 266: 29-33.

de Freitas Balanco JM, Moreira ME, Bonomo A, Bozza PT, Amarante-Mendes G, Pirmez C, Barcinski MA 2001. Apoptotic mimicry by an obligate intracellular parasite downregulates macrophage microbicidal activity. Curr Biol 11: 1870-1873. de Meis J, Ferreira LM, Guillermo LV, Silva EM, DosReis GA, Lopes MF 2008. Apoptosis differentially regulates mesenteric and subcutaneous lymph node immune responses to Trypanosoma cruzi. Eur J Immunol 38: 139-146.

de Meis J, Mendes-da-Cruz DA, Farias-de-Oliveira DA, Corrêa-deSantana E, Pinto-Mariz F, Cotta-de-Almeida V, Bonomo A, Savino W 2006. Atrophy of mesenteric lymph nodes in experimental Chagas' disease: differential role of Fas/Fas-L and TNFRI/TNF pathways. Microbes Infect 8: 221-231.

de Oliveira GM, Diniz RL, Batista W, Batista MM, Bani Correa C, de Araújo-Jorge TC, Henriques-Pons A 2007. Fas ligand-dependent inflammatory regulation in acute myocarditis induced by Trypanosoma cruzi infection. Am J Pathol 171: 79-86.

de Souza EM, Araújo-Jorge TC, Bailly C, Lansiaux A, Batista MM, Oliveira GM, Soeiro MN 2003. Host and parasite apoptosis following Trypanosoma cruzi infection in in vitro and in vivo models. Cell Tissue Res 314: 223-235.

DosReis GA, Freire-de-Lima CG, Nunes MP, Lopes MF 2005. The importance of aberrant T-cell responses in Chagas disease. Trends Parasitol 21: 237-243.

DosReis GA, Ribeiro-Gomes FL, Guillermo LV, Lopes MF 2007. Cross-talk between apoptosis and cytokines in the regulation of parasitic infection. Cytokine Growth Factor Rev 18: 97-105.

Eriksson U, Ricci R, Hunziker L, Kurrer MO, Oudit GY, Watts TH, Sonderegger I, Bachmaier K, Kopf M, Penninger JM 2003. Dendritic cell-induced autoimmune heart failure requires cooperation between adaptive and innate immunity. Nat Med 9: 1484-1490.

Fadok VA, Bratton DL, Konowal A, Freed PW, Westcott JY, Henson PM 1998. Macrophages that have ingested apoptotic cells in vitro inhibit proinflammatory cytokine production through autocrine/ paracrine mechanisms involving TGF-beta, PGE2, and PAF. J Clin Invest 101: 890-898.

Freire-de-Lima CG, Nascimento DO, Soares MB, Bozza PT, CastroFaria-Neto HC, de Mello FG, DosReis GA, Lopes MF 2000. Uptake of apoptotic cells drives the growth of a pathogenic trypanosome in macrophages. Nature 403: 199-203.

Guillermo LV, Pereira WF, De Meis J, Ribeiro-Gomes FL, Silva EM, Kroll-Palhares K, Takiya CM, Lopes MF 2009. Targeting caspases in intracellular protozoan infections. Immunopharmacol Immunotoxicol 31: 159-173.

Guillermo LV, Silva EM, Ribeiro-Gomes FL, De Meis J, Pereira WF, Yagita H, DosReis GA, Lopes MF 2007. The Fas death pathway controls coordinated expansions of type 1 CD8 and type 2 CD4 T cells in Trypanosoma cruzi infection. J Leukoc Biol 81: 942-951.

Hanayama R, Tanaka M, Miwa K, Shinohara A, Iwamatsu A, Nagata S 2002. Identification of a factor that links apoptotic cells to phagocytes. Nature 417: 182-187.

Harel-Bellan A, Joskowicz M, Fradelizi D, Eisen H 1983. Modification of T-cell proliferation and interleukin-2 production in mice infected with Trypanosoma cruzi. Proc Natl Acad Sci USA 80: 3466-3469.

Hideko Tatakihara VL, Cecchini R, Borges CL, Malvezi AD, Graçade Souza VK, Yamada-Ogatta SF, Rizzo LV, Pinge-Filho P 2008. Effects of cyclooxygenase inhibitors on parasite burden, anemia and oxidative stress in murine Trypanosoma cruzi infection. FEMS Immunol Med Microbiol 52: 47-58.

Krammer PH, Arnold R, Lavrik IN 2007. Life and death in peripheral T cells. Nat Rev Immunol 7: 532-542.

Leguizamón MS, Mocetti E, García Rivello H, Argibay P, Campetella O 1999. Trans-sialidase from Trypanosoma cruzi induces 
apoptosis in cells from the immune system in vivo. $J$ Infect Dis 180: 1398-1402.

Lopes MF, Cunha JM, Bezerra FL, Gonzalez MS, Gomes JE, Lapa e Silva JR, Garcia ES, DosReis GA 1995a. Trypanosoma cruzi: both chemically induced and triatomine-derived metacyclic trypomastigotes cause the same immunological disturbances in the infected mammalian host. Exp Parasitol 80: 194-204.

Lopes MF, da Veiga VF, Santos AR, Fonseca ME, DosReis GA 1995b. Activation-induced CD4+ T cell death by apoptosis in experimental Chagas' disease. J Immunol 154: 744-752.

Lopes MF, DosReis GA 1996. Trypanosoma cruzi-induced immunosuppression: selective triggering of $\mathrm{CD} 4+\mathrm{T}$-cell death by the T-cell receptor-CD3 pathway and not by the CD69 or Ly- 6 activation pathway. Infect Immun 64: 1559-1564.

Lopes MF, Nunes MP, Henriques-Pons A, Giese N, Morse HC 3rd, Davidson WF, Araújo-Jorge TC, DosReis GA 1999. Increased susceptibility of Fas ligand-deficient gld mice to Trypanosoma cruzi infection due to a Th2-biased host immune response. Eur $J$ Immunol 29: 81-89.

Lucas M, Stuart LM, Savill J, Lacy-Hulbert A 2003. Apoptotic cells and innate immune stimuli combine to regulate macrophage cytokine secretion. J Immunol 171: 2610-2615.

Marañón C, Planelles L, Alonso C, López MC 2000. HSP70 from Trypanosoma cruzi is endowed with specific cell proliferation potential leading to apoptosis. Int Immunol 12: 1685-1693.

Martins GA, Cardoso MA, Aliberti JC, Silva JS 1998. Nitric oxideinduced apoptotic cell death in the acute phase of Trypanosoma cruzi infection in mice. Immunol Lett 63: 113-120.

Michelin MA, Silva JS, Cunha FQ 2005. Inducible cyclooxygenase released prostaglandin mediates immunosuppression in acute phase of experimental Trypanosoma cruzi infection. Exp Parasitol 111: 71-79.

Minoprio P, Itohara S, Heusser C, Tonegawa S, Coutinho A 1989. Immunobiology of murine T. cruzi infection: the predominance of parasite-nonspecific responses and the activation of TCRI T cells. Immunol Rev 112: 183-207.

Nunes MP, Andrade RM, Lopes MF, DosReis GA 1998. Activationinduced T-cell death exacerbates Trypanosoma cruzi replication in macrophages cocultured with CD4+ T lymphocytes from infected hosts. J Immunol 160: 1313-1319.

Pereira NA, Song Z 2008. Some commonly used caspase substrates and inhibitors lack the specificity required to monitor individual caspase activity. Biochem Biophys Res Commun 377: 873-877.

Petersen CA, Krumholz KA, Carmen J, Sinai AP, Burleigh BA 2006. Trypanosoma cruzi infection and nuclear factor kappa B activation prevent apoptosis in cardiac cells. Infect Immun 74: $1580-1587$

Piacenza L, Peluffo G, Radi R 2001. L-arginine-dependent suppression of apoptosis in Trypanosoma cruzi: contribution of the nitric oxide and polyamine pathways. Proc Natl Acad Sci USA 98: 7301-7306.

Ravichandran KS, Lorenz U 2007. Engulfment of apoptotic cells: signals for a good meal. Nat Rev Immunol 7: 964-974.
Rodrigues V Jr, Agrelli GS, Leon SC, Silva Teixeira DN, Tostes S Jr, Rocha-Rodrigues DB 2008. Fas/Fas-L expression, apoptosis and low proliferative response are associated with heart failure in patients with chronic Chagas' disease. Microbes Infect 10: 29-37.

Rudin CM, Thompson CB 1997. Apoptosis and disease: regulation and clinical relevance of programmed cell death. Annu Rev Med 48: 267-281.

Savill J, Hogg N, Ren Y, Haslett C 1992. Thrombospondin cooperates with $\mathrm{CD} 36$ and the vitronectin receptor in macrophage recognition of neutrophils undergoing apoptosis. J Clin Invest 90: $1513-1522$.

Silva EM, Guillermo LV, Ribeiro-Gomes FL, De Meis J, Nunes MP, Senra JF, Soares MB, DosReis GA, Lopes MF 2007. Caspase inhibition reduces lymphocyte apoptosis and improves host immune responses to Trypanosoma cruzi infection. Eur J Immunol 37: 738-746.

Silva EM, Guillermo LV, Ribeiro-Gomes FL, De Meis J, Pereira RM, Wu Z, Calegari-Silva TC, Seabra SH, Lopes UG, Siegel RM, Dosreis GA, Lopes MF 2005. Caspase-8 activity prevents type 2 cytokine responses and is required for protective T cell-mediated immunity against Trypanosoma cruzi infection. J Immunol 174: 6314-6321.

Tostes S Jr, Bertulucci Rocha-Rodrigues D, de Araujo Pereira G, Rodrigues V Jr 2005. Myocardiocyte apoptosis in heart failure in chronic Chagas' disease. Int J Cardiol 99: 233-237.

Tóth B, Garabuczi E, Sarang Z, Vereb G, Vámosi G, Aeschlimann D, Blaskó B, Bécsi B, Erdõdi F, Lacy-Hulbert A, Zhang A, Falasca L, Birge RB, Balajthy Z, Melino G, Fésüs L, Szondy $Z$ 2009. Transglutaminase 2 is needed for the formation of an efficient phagocyte portal in macrophages engulfing apoptotic cells. J Immunol 182: 2084-2092.

van Zandbergen G, Bollinger A, Wenzel A, Kamhawi S, Voll R, Klinger M, Müller A, Hölscher C, Herrmann M, Sacks D, Solbach W, Laskay T 2006. Leishmania disease development depends on the presence of apoptotic promastigotes in the virulent inoculum. Proc Natl Acad Sci USA 103: 13837-13842.

Voll RE, Herrmann M, Roth EA, Stach C, Kalden JR, Girkontaite I 1997. Immunosuppressive effects of apoptotic cells. Nature 390: $350-351$.

Welsh RM, McNally JM 1999. Immune deficiency, immune silencing and clonal exhaustion of $\mathrm{T}$ cell responses during viral infections. Curr Opin Microbiol 2: 382-387.

Wu Z, Roberts M, Porter M, Walker F, Wherry EJ, Kelly J, Gadina M, Silva EM, DosReis GA, Lopes MF, O'Shea J, Leonard WJ, Ahmed R, Siegel RM 2004. Viral FLIP impairs survival of activated $\mathrm{T}$ cells and generation of CD8+ T cell memory. J Immunol 172: 6313-6323.

Zhang J, Andrade ZA, Yu ZX, Andrade SG, Takeda K, Sadirgursky M, Ferrans VJ 1999. Apoptosis in a canine model of acute Chagasic myocarditis. J Mol Cell Cardiol 31: 581-596.

Zuñiga E, Motran CC, Montes CL, Yagita H, Gruppi A 2002. Trypanosoma cruzi infection selectively renders parasite-specific $\mathrm{IgG}+\mathrm{B}$ lymphocytes susceptible to Fas/Fas ligand-mediated fratricide. J Immunol 168: 3965-3973. 